\title{
PERCEPÇÃO DE GESTORES ESCOLARES DE UM PROGRAMA FORMATIVO A DISTÂNCIA SOBRE TEMAS CONTEMPORÂNEOS EM EDUCAÇÃO
}

\author{
José Márcio Silva BARBOSA ${ }^{1}$ \\ Rita Márcia Andrade Vaz de MELLO ${ }^{2}$ \\ Leililene Antunes SOARES ${ }^{3}$
}

RESUMO: O texto visa explorar alguns aspectos que envolvem a pós-graduação (lato sensu) em Gestão Escolar de uma Instituição de Ensino Superior em convênio com o Programa Nacional Escola de Gestores da Educação Básica do Ministério da Educação, que surgiu da necessidade de contribuir com a qualificação de gestores escolares em efetivo exercício na rede pública de ensino no sentido de tratar os aspectos teóricos em articulação com a realidade escolar. Face às complexidades e a diversidade de situações que solicitam intervenções diversas por parte do gestor, que lhes são apresentadas para transformação da realidade escolar e qualidade educacional, o objetivo do artigo é abrir ampla discussão sobre experiências e vivências na prática escolar com as quais se deparam. O procedimento metodológico se deu pela abordagem qualitativa, empregando-se a análise bibliográfica da literatura especializada, sendo a tabulação dos dados obtidos feita pela análise de conteúdo e, cujo lócus de investigação tem como referência as atividades desenvolvidas por gestores-cursistas em três salas ambientes virtuais (Introdução a Plataforma de ensino e ao Curso, Políticas e Gestão da Educação e Planejamento e Práticas da Gestão Escolar) do referido curso. Os estudos revelam que o referido Programa permite importantes contribuições aos aspectos teóricos e práticos necessários ao conhecimento, as reflexões e as orientações educacionais que se fazem aflorar as ações dos gestores escolares, atitudes reflexivas e interventivas em âmbito escolar, no que tange ao trato do seu trabalho pedagógico e administrativo, bem como no diálogo para a construção de realidades mais democráticas e qualitativas da rede pública de ensino.

PALAVRAS-CHAVE: Programa Escola de Gestores. Formação continuada e a distância. Sala ambiente virtual.

\section{INTRODUÇÃO}

Nos últimos tempos, várias políticas, programas e ações estão sendo realizados pelo governo Federal. A tendência atual das reformas educacionais tem na gestão e na escola um de seus pilares de transformação. O governo federal pautou sua atuação pelo

\footnotetext{
${ }^{1}$ UFV - Universidade Federal de Viçosa. Departamento de Educação - Pós-Graduação em Educação. Viçosa - MG - Brasil. 36570-900. Doutorando em Educação. UFMG - Universidade Federal de Minas Gerais. Faculdade de Educação - Pós-Graduação em Educação. Belo Horizonte - MG - Brasil. jmarciosb@yahoo.com.br

${ }_{2}^{2}$ Pós-Doutora. Université Paris Descartes (Sorbonne). Coordenadora de Cursos Lato Sensu. UFV Universidade Federal de Viçosa. Viçosa - MG - Brasil. 36570-900. ritamarciamello@ gmail.com.br

${ }^{3}$ UFV - Universidade Federal de Viçosa. Departamento de Educação - Pós-Graduação em Educação. Viçosa - MG - Brasil. 36570-900. Pós-Graduação em Psicopedagogia. UCB - Universidade Castelo Branco. Pós-Graduação em Educação. Rio de Janeiro - RJ - Brasil. 21710-255. leililene@ yahoo.com.br
} 
principio da defesa da educação de qualidade, estimulando e viabilizando cada vez mais esta realidade.

A ideia de formação continuada é a base dos modelos amplamente aceito e defendido por políticos, educadores, pesquisadores e acadêmicos. Sensível à preocupação sobre a formação de gestores escolares capazes de refletirem sobre suas práticas pedagógicas, as ideias expressas nas salas ambientes do curso de especialização em gestão escolar de uma instituição de ensino superior em convênio com o Programa Nacional Escola de Gestores da educação Básica do Ministério da Educação, o objetivo desse trabalho é refletir sobre as expectativas que manifestam na formação que gestorescursistas estão recebendo em constante diálogo com a realidade escolar, bem como identificar eixos norteadores que podem oferecer indicadores de questionamentos e transformações pontuais, aberto a revisões e aperfeiçoamento constante.

As reflexões emanadas das vivências e da troca de experiência de gestores escolares em que contribuam para a materialização de ações concretas e inovadoras, para o desenvolvimento de práticas de gestão técnico-administrativa, de natureza pedagógica e democrática, de modo a incidir, progressivamente, na melhoria do desempenho escolar, nos processos de solução de problemas, na tomada de decisões e na autonomia na escola, precisam ser contempladas nas oportunidades de formação.

Verifica-se que existem diferentes concepções sobre gestão escolar. Compreender as orientações da gestão escolar requer verificar as especificidades educacionais acerca do profissional que está a frente do cargo de direção escolar. $\mathrm{O}$ sentido mais difundido na atualidade tem sido a gestão democrática, as tecnologias da informação e da comunicação e Plano de Desenvolvimento da Educação (PDE). As possíveis articulações dessas temáticas na gestão escolar têm sido vistos como campo fértil para investigações.

Essa preocupação se dá na perspectiva de que, a partir da aquisição de novos conhecimentos, os gestores escolares possam refletir sobre os desafios da profissão. $\mathrm{O}$ termo gestão democrática da escola pública surge nos discursos dos educadores em defesa da garantia de acesso e qualidade na educação. Perpassa pelas decisões coletivas na escola e na participação em que toda a comunidade escolar está submetida ao aperfeiçoamento administrativo-pedagógico e no desempenho dos alunos.

O PDE contempla como um das mais consagrada política educacional na atualidade ao qual busca incentivar a implementação de novas ações na gestão, para cumprir metas e objetivos considerados urgentes na melhoria da qualidade da educação 
básica. Relacioná-lo com a gestão escolar significa impulsionar ações que precisam ser explicitados, compreendidos e compartilhados nas decisões entre os membros da comunidade escolar, comprometidos com a busca da forma mais adequada em atingir seus objetivos educacionais.

E por último, a Tecnologia da Informação e da Comunicação (TIC) adquire centralidade no processo de gestão escolar, suscitando novas perspectivas para a gestão do processo educativo. Por considerarmos a importância desse componente tecnológico na prática de gestão, à luz de compreensões do âmbito local, é importante compreender as atribuições dadas a este profissional com vistas a promover iniciativas que estimulem o envolvimento de gestores associados á forma como os recursos tecnológicos são projetados, desenvolvidos e integrados em âmbito escolar.

E por compormos a equipe de tutores, professores e coordenadores, a proposta precípua é trazer para o centro das discussões, o enfrentamento dos desafios cotidianos, impostos à sua gestão, no que tange ao envolvimento na tomada de decisões na escola, colaborando para a maximização da organização, desempenho, comunicação e relacionamento interpessoal na gestão escolar.

\section{PROGRAMA NACIONAL ESCOLA DE GESTORES E FORMAÇÃO CONTINUADA EM TEMPOS DE EAD}

Observa-se, pela primeira vez na educação brasileira o crescimento pela busca de formação continuada sob a perspectiva de cursos de Pós-Graduação lato sensu devido à grande expansão de ofertas de cursos na modalidade à distância pelas instituições de ensino superior no país. Em 2006, nasceu o Programa Nacional Escola de Gestores da Educação Básica Pública tendo como objetivos gerais formar, em nível de especialização, gestores educacionais efetivos das escolas públicas da educação básica, incluídos aqueles de educação de jovens e adultos, de educação especial e de educação profissional além de contribuir com a qualificação do gestor escolar na perspectiva da gestão democrática e da efetivação do direito à educação escolar com qualidade social. Além disso, o programa visa incentivar os gestores a refletirem e a desenvolverem práticas educativas inovadoras no ambiente escolar. Em outras palavras, almeja possibilitar oportunidades para ampliação de capacidades como: analisar e resolver problemas, elaborar e desenvolver projetos e atividades na área de gestão com o suporte das tecnologias de informação e comunicação (BRASIL, 2005). 
Considerando o elevado número de profissionais que exercem dupla jornada nas instituições públicas de educação básica, bem como as dificuldades que muitos deles encontram no prosseguimento de seus estudos, a programa tem sido será desenvolvida na modalidade do ensino a distância utilizada como alternativa para ampliar a oferta de cursos de formação continuada e pós-graduada, em especial nas regiões onde a oferta de alternativas de formação se apresenta ainda insuficiente.

Evidencia-se que o curso de pós-graduação em Gestão Escolar não está, embasado somente na capacitação e qualificação profissional, mas há que se garantir, através de um caráter reflexivo, a importância por mudanças em sua prática profissional, para que alcancemos o bom andamento do curso, bem como torna-se também um espaço onde professores e equipe pedagógica constituem um fortes aliados a reflexão e ação de praticas que geram impactos maiores ou menores no cotidiano escolar; o que impõe novas demandas sobre o sistema educacional. Desse modo, as preocupações centram-se nos processos de construção do conhecimento profissional e do docente (gestor) crítico-reflexivo.

O contínuo aperfeiçoamento dos gestores escolares surge como ação fundamental para compreensão coletiva das novas exigências em torno do trabalho pedagógico, da mesma forma que as pesquisas sobre a formação de professores têm redirecionado suas concepções teórico-metodológicas ao cotidiano escolar. Para esse autor, a constatação mais importante foi a da necessidade de uma prática, por meio da qual, ação e reflexão devem caminhar juntas, contribuindo para o diálogo e superação de "situações práticas que são únicas, incertas e conflituosas" (SCHÖN, 2000, p.30). Por isso, sugere uma formação profissional baseada na epistemologia da prática, ou seja, “[...] na valorização da prática profissional como momento de construção de conhecimento, através da reflexão, análise e problematização desta, e o reconhecimento do conhecimento tácito, presente nas soluções que os profissionais encontram em ação." (PIMENTA; GHEDIN, 2005, p.19).

Nesse aspecto, compartilhamos dessa preocupação, atribuindo suas causas a questões internas à vida escolar. A ideia de que a própria escola é o lugar de formação profissional, por ser, sobretudo nela, o trabalho com o qual eles constroem suas práticas, sugere caminhos para o aprofundamento dos estudos.

Aos estudos críticos sobre formação continuada, temos na visão de Gatti e Sá (2009) o argumento de que é a limitada, senão ausente, participação dos professores na definição de politicas de formação docente, como categoria profissional e na formação 
de projetos que têm a escola e o seu fazer pedagógico como centro. Para as autoras, eles não se envolvem, não se apropriam dos princípios, não se sentem estimulados a alterar sua prática, mediante a construção de alternativas de ação, ao mesmo tempo em que se recusam a agir como meros executores de propostas externas. Como as autoras advertem:

As oficinas de reflexão sobre a prática [...] permite maior aderência à realidade do professor e maior atenção ao seu repertório de práticas em culturas escolares diversas, seja para legitimá-las, ressignificá-las ou superá-las [...] a introdução de processos formativos que utilizam a reflexão crítica sobre as práticas no contexto de um compromisso com o fortalecimento da escola, enquanto instituição com responsabilidade social relevante e desafiadora no mundo atual, implica ambientes propícios a trabalho coletivo, gestão participativa e disponibilidade de recursos pedagógicos e materiais apropriados. (GATTI; SÁ, 2009, p.203).

Tais constatações impõem a necessidade de despertar para a intencionalidade de um Programa que objetiva formar o gestor, monitorando-o e avaliando-o permanentemente por meio dos trabalhos postados na plataforma (TEIXEIRA, 2011). Partindo de seus conhecimentos prévios, permeados, inicialmente, pelo senso comum, procurávamos elevar seus conhecimentos ao patamar científico, estabelecendo mediações com a realidade escolar em que atuavam (QUEIROZ; GADELHA, 2012). Essas constatações na concepção de formação do gestor indicam mais do que alcançar a interpretação compartilhada da informação a partir da sua disseminação, sendo necessário mostrar como os gestores-cursistas questionam ou utilizam o conteúdo curricular como base para a ação. Essas são questões importantes, levantadas na investigação sobre o assunto, que podem ser consideradas um caminho para uma educação inovadora, segundo uma roupagem caracterizada pela interatividade, cabendo a ele criar um posicionamento de protagonista sobre essa nova perspectiva da escola reflexiva, de formação inicial e continuada, do desenvolvimento do profissional, que ocorre durante a vida do professor, na sua interação com a sua prática, com o coletivo escolar e com o contexto organizacional no qual estão inseridos (RIVAS et al., 2005).

Não se pode deixar de considerar como fundamental para a formação de gestores a implantação do curso de pós-graduação na modalidade de ensino a distância pelas instituições de Ensino Superior. O fato concreto de que teremos um contingente cada vez maior de professores que fazem a opção por uma formação vinculada a um curso de pós-graduação lato sensu, algo que não é descontextualizado da realidade da educação 
básica, configurando-se como uma constante e parece que veio para ficar, impondo às Universidades e em especial aos Programas de Pós-Graduação de todo o Brasil o debate acerca do papel social em que cada docente deve exercer em favor da melhoria das condições de trabalho e da sua valorização profissional (CANDEIAS, 2013).

A Universidade Federal de Viçosa conta com o apoio da plataforma PVANET (PVA vem da abreviatura de Pavilhão de Aula e net, de internet) - implantada pela Coordenadoria de Educação Aberta e a Distância (CEAD) considerada um Ambiente de Aprendizagem Virtual que por meio de sua organização, funcionamento e acesso ao ensino a distância, vem oportunizando aos cursistas de diversas regiões à construção de novos conhecimentos, saberes e formação (BRASIL, 2005). A partir da sua implantação, os gestores-cursistas tem a possibilidade de realizar sua capacitação por meio do ensino virtual e presencial, compartilhando críticas, temáticas e problematização na apropriação de conteúdos disponível na plataforma virtual.

Assim, os gestores-cursistas tem a sua disposição uma gama de estratégias e de instrumentos que vem a favorecer a acessibilidade e integração com os recursos tecnológicos tais como vídeos, Chats, fórum e atividades avaliativas, no intuito de responder, questionar e apropriar de novos conhecimentos. Ao elaborarem e responderem questões sobre determinados temas, os alunos desenvolvem uma atitude crítica frente ao aprendizado e constroem seu próprio conhecimento.

No que concerne particularmente à modalidade $\mathrm{EaD}$ nesse programa, vale salientarmos que ela assume um papel importante, sendo talvez um condição indispensável para sua realização. Propiciar um movimento de reflexão teórico e prático entre conteúdos e atividade propostas no ambiente do curso a distância tem sido o ideal da formação profissional. Esses são as propostas utilizadas pelo Ministério da Educação para atualizar a prática educacional, visando a trazer os profissionais para os anseios educacionais contemporâneos e para a melhoria da qualidade da educação no país. Em consonância com esse argumento, a crescente socialização destes meios nos impõe com responsabilidade social, o repensar dos processos organizativos da aprendizagem, que incluam o uso das tecnologias da informação e da comunicação (RINALDI; DALFORNO; REALI, 2009). 


\section{PROCEDIMENTOS METODOLÓGICOS}

Para a imersão no contexto a ser estudado, a metodologia de pesquisa qualitativa orienta o trabalho investigativo na compreensão de questões, conceitos ou fenômenos, descrevendo-os e interpretando-os no intuito de subsidiar informações, afirmações e depoimentos que justifiquem o trabalho da pesquisa. A definição do método qualitativo pode ser entendida como procedimento e instrumento de coleta de dados que permite a sistematização dos estudos bibliográficos realizados, no sentido de conhecer os caminhos que pontuam a discussão do tema proposto (ALVES-MAZZOTTI; GEWANDSZAJDER, 1998). Empreendedora de amplos estudos e rica metodologicamente, a abordagem qualitativa permite trabalhar o material durante a pesquisa com sua organização e maior exploração possibilitando a articulação entre os pressupostos teóricos do estudo e os dados da realidade para melhor compreensão dos fenômenos que poderão emergir no cotidiano da escola (LÜDKE; ANDRÉ, 1986).

Para alcançar essas definições, supõe-se que a análise de conteúdo seja uma entre as diferentes formas de interpretar o conteúdo de um texto que se desenvolveu adotando normas sistemáticas de extrair os significados temáticos. Esta análise consiste em relacionar a frequência da citação de alguns temas, palavras ou ideias ou constância dessas unidades para fazer inferências e extrair os significados inscritos no texto com base nos indicadores objetivos (CHIZZOTTI, 2006). Dada a multiplicidade de uma série de respostas obtidas pelas quais a realidade escolar se manifesta, abre-se igualmente um campo de reflexões e argumentações por parte dos respondentes, surgindo diversas categorias de análise. Desse modo, a eleição de categorias é fundamental para atingir os objetivos que se pretende, pois, para o autor estas categorias devem estar claramente definidas e ser pertinentes aos objetivos pretendidos na pesquisa (CHIZZOTTI, 2006).

Nesse contexto, o campo da pesquisa fica circunscrito à formação continuada de gestores escolares no curso de Pós-Graduação (lato sensu) em Gestão Escolar de uma Universidade Federal, no âmbito do Programa Nacional Escola de Gestores da Educação Básica do Ministério da Educação, devido à constatação de que os órgãos executores dispõem de toda documentação necessária para auxiliar na investigação. Para um referencial interpretativo, as formas de tratamento poderão gerar uma confiabilidade do resultado a ser apresentado pela visão geral da sala ambiente virtual do curso de especialização em Gestão Escolar, por este curso ter conteúdos curriculares 
que nos permitem destacar dimensões e tendências iniciais de análise ou mesmo das relações esperadas.

A análise dos dados foi obtida através de gestores-cursistas que deram voz a essa discussão e por quem realiza o curso de formação continuada de gestores escolares pela Instituição de Ensino Superior. Para a sistematização de informações escolheu-se três salas ambientes virtuais (Introdução à Plataforma e ao curso, Política e Gestão da Educação e Planejamento e Práticas da Gestão Escolar) do curso de pós-graduação (lato sensu) em Gestão Escolar e que são provedores de conceitos e conteúdos teóricos, necessários para a base de conhecimentos existente no cabedal do curso. Escolhemos a turma de 2013, composta por vinte e três gestores-cursistas, sendo que todos eles atuam na rede pública de ensino ou exercem função equivalente na instituição de ensino. As atividades que compõem a sala ambiente virtual foram realizadas em grupo e na sua maioria, trabalham na mesma escola. Isto tem sido importante para construir espaço privilegiado para debates, reflexões, discussões e socialização de ideias. A seguir, apresentamos alguns extratos das manifestações de gestores-cursistas que apontam objetivamente a questão proposta.

\section{RESULTADOS E DISCUSSÃO}

Para as seções que se seguem buscaremos apresentar a possibilidade do desenvolvimento de práticas e de organização do trabalho pedagógico que contribuam para um desempenho efetivo no interior da gestão escolar, seja nas condições materiais e institucionais, valorizando a vivência investigativa e informativa num processo de construção da prática qualificada e de profissionalização docente (gestor).

O Curso de especialização em Gestão escolar é estruturado por salas ambientes virtuais que são disponibilizadas atividades de caráter teórico-prático. Tomamos como referências as salas ambientes virtuais, pois, permite maior aderência à realidade do gestor-cursista, interpenetrando na atuação do profissional docente (gestor) no sentido de propiciar ações interventivas e inovadoras no espaço escolar.

A sala ambiente virtual Introdução a Plataforma de Ensino e ao curso consiste em um espaço onde serão desenvolvidas atividades de ambientação dos professoresgestores em relação às ferramentas tecnológicas que serão disponibilizadas durante o processo formativo e forneça uma visão geral do curso. Essa disciplina vai possibilitar o conhecimento do ambiente do curso bem como a metodologia de educação a distância, não só para acessar todo o material de aula de cada disciplina, mas também explorar as 
diversas ferramentas e recursos disponíveis, com a possibilidade de interação entre todos os envolvidos no curso. Outro objetivo visado é o fomento do uso de ferramentas tecnológicas no intuito de desenvolver a criatividade desses sujeitos em propor inovações em suas práticas escolares. Com base no exposto espera-se que o Gestor Escolar seja capaz de além de dominar e utilizar ferramentas tecnológicas no campo da organização dos processos de trabalho nos sistemas e unidades de ensino, tomando-as como importantes ferramentas para realização da gestão democrática da educação.

E para instigar o debate entre os gestores-cursistas, um tema que tem sido bastante difundido e invocado a um fazer docente (gestor) consciente de sua ação, está associado à utilização das TIC como meio de potencializar o processo de construção do conhecimento e de cidadania. Além de apoiar as práticas pedagógicas na escola, as TIC significam um importante instrumento que propicia a interação entre os atores do processo educacional. Nesse sentido, apropriamos de atividade desenvolvida na plataforma virtual em que eles deveriam refletir sobre o uso e apropriação das TIC no ambiente escolar. E é neste ambiente de aprendizagem que permitiu a apreensão, interpretação e descrição do uso e da apropriação das TIC por gestores escolares. A palavra-chave é integrar o humano e o tecnológico, dentro de uma visão pedagógica nova, criativa e aberta (MORAN, 1997). A seguir são apresentados alguns trechos em que se basearam as análises empreendidas.

Quadro 1 - Listagem das discussões observadas por gestores escolares e selecionadas na Sala Ambiente Virtual

\begin{tabular}{|c|c|c|}
\hline $\begin{array}{c}\text { Sala Ambiente } \\
\text { Virtual }\end{array}$ & $\begin{array}{l}\text { Tema em } \\
\text { educação }\end{array}$ & Relatos de Gestores-cursistas \\
\hline $\begin{array}{l}\text { Introdução à } \\
\text { Plataforma e } \\
\text { ao curso }\end{array}$ & $\begin{array}{l}\text { Tecnologia da } \\
\text { Informação e da } \\
\text { Comunicação }\end{array}$ & $\begin{array}{l}\text { "Insuficiência de computadores e laboratório de informática no } \\
\text { espaço escolar"; "falta de incentivo dos profissionais da educação } \\
\text { em manusear as ferramentas tecnológicas"; "a importância do } \\
\text { envolvimento de toda a equipe escolar à incorporação das TIC na } \\
\text { sala de aula"; "dificuldades em aproximar escola e realidade do } \\
\text { aluno no auxílio da aprendizagem" e "necessidade de treinamento } \\
\text { profissional". }\end{array}$ \\
\hline
\end{tabular}

Fonte: Elaboração própria, com base em dados da pesquisa.

Essas observações sugerem que o gestor escolar, por meio do processamento de informações obtidas no ambiente virtual, onde se aplicam os fundamentos teóricos apreendidos, instigue a discussão sobre ações que promovam uma associação com a dinâmica de trabalho, nas decisões e nas atitudes inovadoras no ambiente escolar, bem como tragam consigo a geração de novas informações com orientação no cotidiano da 
escola. A sala ambiente virtual Politicas e Gestão da Educação procura fazer uma ligação muito imbricada entre gestão escolar e politicas públicas em educação. Percebemos que o conceito de gestão nessa sala está ligado também aos conceitos de gestão democrática e participação como processo em construção. E estas passam a ocupar o centro de atenções e intenções aos projetos de ação e formação continuada de gestores escolares.

A concepção de gestão democrática adotada no curso apresenta um paradoxo com outras concepções de gestão adotadas em programas do MEC para os sistemas de ensino. A gestão democrática como princípio da educação nacional, presença obrigatória em instituições escolares constitui-se na forma com que a comunidade educacional se organiza, coletivamente, para levar, a termo, um projeto políticopedagógico de qualidade, ao mesmo tempo em que contribui na formação de cidadãos críticos e compromissados com a transformação social (BRASIL, 2005). O programa objetiva contrapor o paradigma da gestão democrática da escola às concepções centralizadoras e hierarquizadas de gestão escolar. Ela tem que ser pensada no trabalho em grupo, na participação e no processo de democratização nas decisões do processo educativo entre toda a comunidade escolar, resultando assim na democratização das relações que se desenvolvem na escola, contribuindo para o aperfeiçoamento do trabalho administrativo e pedagógico. Vejamos o que nos apontam os gestores-cursistas:

Quadro 2 - Listagem das discussões observadas por gestores escolares e selecionadas na Sala Ambiente Virtual

\begin{tabular}{|c|c|c|}
\hline $\begin{array}{c}\text { Sala } \\
\text { Ambiente } \\
\text { Virtual }\end{array}$ & $\begin{array}{l}\text { Tema em } \\
\text { Educação }\end{array}$ & Relatos de Gestores-cursistas \\
\hline $\begin{array}{l}\text { Política e } \\
\text { Gestão da } \\
\text { Educação }\end{array}$ & $\begin{array}{c}\text { Gestão } \\
\text { democrática }\end{array}$ & $\begin{array}{l}\text { "Autonomia, envolvimento e participação da comunidade escolar são } \\
\text { condições fundamentais para que a escola se torne democrática"; "A falta } \\
\text { de comprometimento de alguns profissionais da educação e falta de } \\
\text { comunicação são entraves no desenvolvimento da autonomia da escola"; } \\
\text { "Como esperar uma gestão democrática na escola se os atores envolvidos } \\
\text { não conhecem seus papéis a serem desempenhados na construção do } \\
\text { processo"; "A verdadeira ideia de gestão democrática muitas vezes não é } \\
\text { trabalhada na prática com os participes da escola, ficando a questão tratada } \\
\text { apenas no plano teórico, ou seja, muitas vezes as ações são efetivadas } \\
\text { apenas no papel, não tendo a participação ativa das pessoas envolvidas na } \\
\text { prática das ações, muitas vezes por não saber como se envolver"; "a gestão } \\
\text { democrática é um processo complexo, mas não irrealizável, e que exige de } \\
\text { todos os envolvidos neste processo (família, profissionais, governo e } \\
\text { sociedade), ações imediatas e sólidas que garantam a concretização das } \\
\text { ações de um trabalho coletivo, com o propósito de substituir o paradigma }\end{array}$ \\
\hline
\end{tabular}


Fonte: Elaboração própria, com base em dados da pesquisa.

Gerir democraticamente, por sua vez, significa usar de todas as estratégias que ela oferece como pressuposto fundamental a ser implementada na escola. Consideramos estes aspectos como um avanço nas ações inovadoras na escola, uma vez que permite aprofundar e organizar sobre a relação entre a teoria e a prática com base na concepção da gestão democrática no ambiente escolar, favorecendo o trabalho coletivo e as dimensões da construção do trabalho pedagógico. O programa reconhece a centralidade da formação dos gestores escolares no avanço da qualidade do ensino e na realização e fortalecimento da gestão democrática da educação pública. Um dos pressupostos imprescindíveis na formação de gestores (as) escolares está baseado no principio da gestão democrática e de participação entre os membros da comunidade escolar para o alcance da qualidade (CURY, 2002; PARO, 2000; LIBÂNEO; OLIVEIRA; TOSCHI, 2010).

A sala ambiente virtual Planejamento e Práticas de Gestão Escolar estão voltadas às questões de planejamento, prática e avaliação. É na gestão da educação e da escola que a concepção de estrutura, organização e funcionamento da escola é tomada como força e ideia na concepção do programa. Nela é possível trazer para a discussão, como por exemplo, o Plano de Desenvolvimento da Educação que se mantem na pauta dos debates, visando tornar suas ações mais eficientes e produtivas.

Quadro 3 - Listagem das discussões observadas por gestores escolares e selecionadas na sala ambiente virtual

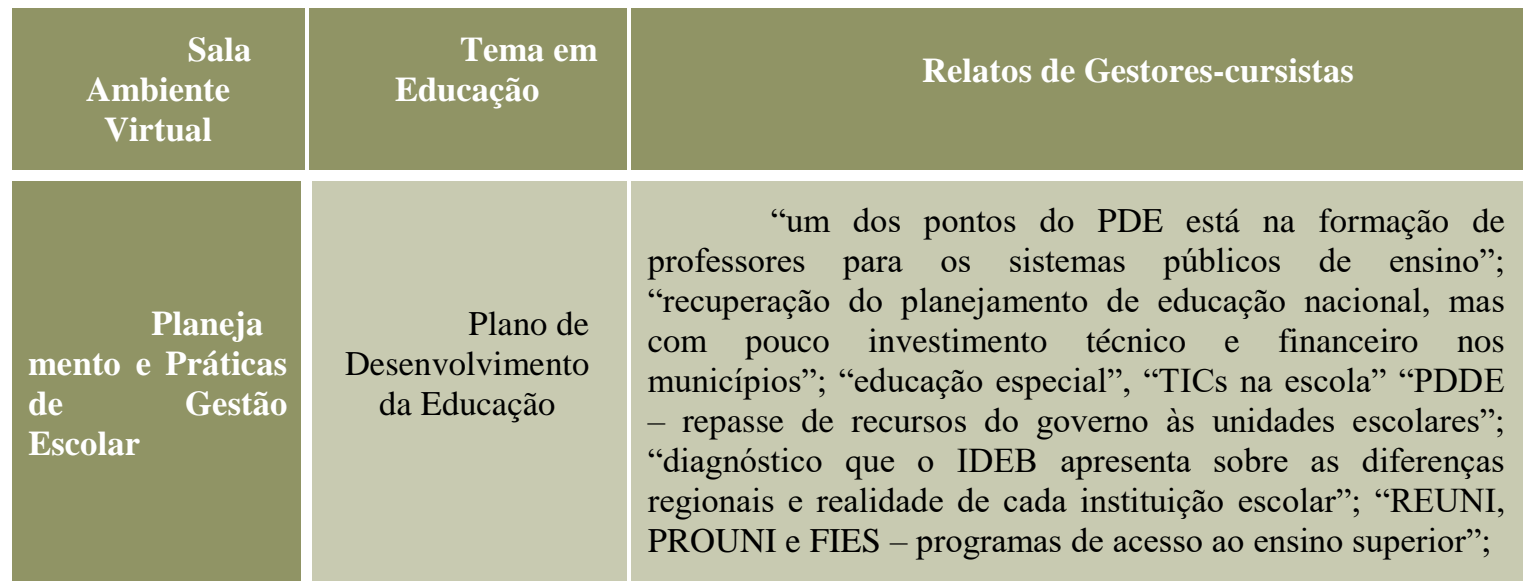

Fonte: Elaboração própria, com base em dados da pesquisa. 
Mediante a complexidade de tarefas e propostas para promover mudanças na gestão, foi solicitado aos gestores-cursistas destacar as ações do PDE que considera relevante, explicitando as possíveis ações que vem fortalecendo o desenvolvimento profissional e a sua atuação no espaço escolar. E pelo fato do programa Nacional Escola de Gestores da Educação Básica Pública compor o Plano de Metas "Compromisso Todos pela Educação" e integrar o Plano de Desenvolvimento da Educação (PDE), articulando-se, portanto, às ações ministeriais de mobilização em torno da melhoria da Educação Básica e do fortalecimento da escola pública brasileira, observa que os próprios gestores assumem uma posição de defesa do processo, como protagonista dos mesmos.

Registra-se uma lista de ações e atribuições que os gestores consideram estratégicos para melhor trabalho na gestão escolar. Podemos afirmar que as ações, metas e propostas do PDE têm proporcionado reflexões e mudanças na realidade escolar. Isto nos levam a afirmar que o papel mediador entre os profissionais da educação e o programa do MEC tem alcançado o seu objetivo maior que é identificar as possíveis ações inovadoras na escola e sua implementação, a fim de favorecer a ampliação de capacidades no desenvolvimento de projetos e atividades na área de gestão, no intuito de melhorar a qualidade educacional.

Podemos afirmar que a opinião unânime dos gestores-cursistas sobre a formação continuada de forma geral, contribui para mudanças significativas em suas práticas pedagógicas, atualizando-os e motivando a transformação de seu trabalho considerando o contexto singular da instituição. Pelas informações coletadas, pode-se perceber que, para o grupo investigado, a formação obtida no curso Lato Sensu do Programa Nacional da Escola de Gestores oferecido pela instituição favoreceu uma articulação entre os princípios teóricos estudados e os instigou a reflexão sobre práticas pedagógicas desenvolvidas por estes no contexto escolar. Nesse sentido, o curso de Pós-Graduação em Gestão Escolar não está isolado da prática reflexiva dos gestores-cursistas no contexto amplo do seu trabalho, aumentando de maneira significativa o pensamento reflexivo do gestor e a relação que este faz entre teoria e prática.

\section{CONSIDERAÇÕES FINAIS}

Com base nas opiniões e nas reflexões produzidas, constata-se um movimento marcado por momentos de avanços e recuos. Por isso, os desafios presentes na educação 
contemporânea se mantêm na pauta dos debates. Compreende-se que a gestão escolar tem sido o centro de implicações, e de iniciativas para qualquer mudança no processo de ensino e aprendizagem, na qualidade de ensino e na execução de práticas educacionais, exigindo dos gestores uma visão clara e precisa sobre a realidade escolar.

Ao reconhecer essa tendência, chama-nos a atenção, em especial, o processo de formação continuada, fundamental para que os gestores escolares possam trazer, em suas experiências profissionais, pistas para o enfrentamento dos desafios cotidianos em permanente diálogo, ao articular a realidade da escola com os conhecimentos obtidos no curso. É importante que haja a condição necessária para a abertura de espaços reflexivos e que estes sejam capazes de propiciar um contínuo repensar de suas funções e responsabilidades no contexto das transformações da sociedade na qual a escola está inserida. Isso implica dizer que o Programa reconhece o diálogo reflexivo entre os gestores cursistas, como objetivo a ser alcançado para apontar os caminhos a serem percorridos na estruturação de uma iniciativa que proporcione resultados condizentes com as necessidades dos profissionais, sem perder de vista o foco da capacitação de gestores, pautado nas práticas de gestão democrática e inovadora.

É preciso pensar a formação continuada de gestores como momentos do processo de construção de prática pedagógica inovadora o que remete ao reflexo do que está sendo defendido por ele no que diz respeito aos princípios e conceitos construído no curso de especialização e no ambiente escolar, de modo que as experiências articuladas no conjunto tragam benefícios para a atuação dos profissionais da gestão.

Nessa linha, as preocupações sobre a formação de gestores escolares se aproximam de um senso de análise crítica não só dos conteúdos ensinados, mas também de situações da vida cotidiana da escola, por quem possa identificar, questionar e refletir sobre as fragilidades percebidas no encaminhamento e execução de determinada ação pedagógica para melhoria da qualidade escolar, bem como constituir uma rede nacional de troca de experiências.

Acreditamos que para estruturar um plano de ação ético, estratégico e eficaz, que realmente atenda às necessidades dos gestores escolares na unidade escolar, seria necessário fazer um diagnóstico dos problemas enfrentados pela escola como um todo e em suas respectivas salas de aula, bem como das necessidades, particularmente, em relação a conhecimentos dos docentes (gestores), a fim de possibilitar-lhes resolver seus problemas diários e apresentar possíveis soluções. 


\section{SCHOOL MANAGERS PERCEPTION ON A DISTANCE PROGRAM ABOUT CONTEMPORARY THEMES IN EDUCATION}

ABSTRACT: The proposed analysis, in this article, aims to explore some aspects that involve graduate school (lato sensu) in School Management at a higher education institution in partnership with Ministry of Education's Basic Education Managers School National Program, that came up with the need to contribute with the qualification of school managers in effective exercise in the public school system in order to deal with the theoretical aspects in articulation with school reality. Given the complexity and the diversity of situations that request several interventions by the manager, that are presented to him to transform the school reality and education quality, the objective of this article is to open wide discussion over experiences in school practice with which the managers face. The methodological procedure was through a qualitative approach, applying the literature review, and the data tabulation made by content analysis and whose research locus has as reference activities developed by managers in three virtual environment rooms (Introduction to teaching Platform and Course, Politics and Education Management and School Management Planning and Practices) of its course. Studies reveal that the Program allows important contributions to theoretical and practical aspects necessary to knowledge, thoughts and education orientations that bring out school managers actions, thoughtful and interventional attitudes in school environment regarding the treatment of their pedagogical and administrative work, as well as in dialogue to build more democratic and qualitative realities in public school.

KEYWORDS: Managers School Program Ongoing and distance training. Virtual Environment Room. Themes in education.

\section{REFERENCIAS}

ALVES-MAZZOTTI, A. J.; GEWANDSZADJER. O planejamento de pesquisas qualitativas. In: . O método nas ciências naturais e sociais: pesquisa quantitativa e qualitativa. São Paulo: Pioneira, 1998, p. 147-178.

BRASIL. Ministério da Educação. Programa Nacional Escola de Gestores da Educação Básica Pública. 2005. Disponível em: <http://portal.mec.gov.br/escola-degestores-da-educacao-basica>. Acesso em: 10 set. 2015.

CANDEIAS, C. N. B. Formação de professores, tecnologias da informação e comunicação e pós-graduação: uma possível articulação. Educação em perspectiva, Viçosa, v.4, n.2, p.372-390, jul/dez. 2013.

CHIZZOTTI, A. Pesquisa qualitativa em ciências humanas e sociais. Petrópolis, RJ: Vozes, 2006.

CURY, C. R. J. Gestão democrática da educação: exigências e desafios. Revista Brasileira de Política e Administração da Educação, Goiânia v.18, n.2, p.63-174, jul/dez. 2002. 
GATTI, B.; SÁ, E. B. Professores do Brasil: impasses e desafios. Brasília: UNESCO, 2009. Disponível em:

<http://unesdoc.unesco.org/images/0018/001846/184682POR.pdf >. Acesso em: 10 set. 2015.

LIBÂNEO, J. C.; OLIVEIRA, J. F.; TOSCHI, M. S. Educação escolar: políticas, estrutura e organização. 9.ed. São Paulo: Cortez, 2010.

LÜDKE, M.; ANDRÉ, M. E. D. A. A análise de dados e algumas questões relacionadas à objetividade e à validade nas abordagens qualitativas. In: (Org.). Pesquisa em Educação: abordagens qualitativas. São Paulo: EPU, 1986. p.45-53.

MORAN, J.M. Como utilizar a Internet na educação. Ciência da Informação, Brasilia, v.26, n.2, p.1-8, maio/ago. 1997. Disponível em:

<http://www.scielo.br/pdf/ci/v26n2/v26n2-5.pdf>. Acesso em: 10 set. 2015.

PARO, V. H. Administração escolar: introdução crítica. 9.ed. São Paulo: Cortez, 2000.

PIMENTA, S. G.; GHEDIN, E. Professor reflexivo no Brasil: gênese e crítica de um conceito. 3.ed. São Paulo: Cortez, 2005.

QUEIROZ, M.A.; GADELHA, M. J.A. Formação de Gestores Escolares a distância: avaliação do ensino e aprendizagem em ambiente virtual. In: CONGRESSO IBERO AMERICANO DE POLÍTICA E ADMINISTRAÇÃO DA EDUCAÇÃO, 3., 2012 , Zaragonza. Anais... Fortaleza: Ed. da Biblioteca ANPAE, 2012. p.1-12. (Cadernos ANPAE). Disponível em:

<http://www.anpae.org.br/iberoamericano2012/Trabalhos/MariaAparecidaDeQueiroz_r es_int_GT2.pdf $>$. Acesso em: 10 set. 2015.

RINALDI, R. P.; DAL-FORNO, J. P.; REALI, A.M. M. R. Programa de desenvolvimento profissional online para formadores em inicio de carreira na educação básica. In: REUNIÃO DA ASSOCIAÇÃO NACIONAL DE PÓS-GRADUAÇÃO E PESQUISA EM EDUCAÇÃO, 32., Caxambú. Anais... Timbaúba: Espaço Livre, 2009. p.1-17. Disponível em: <http://www.32reuniao.anped.org.br/arquivos/trabalhos/GT165708--Int.pdf $>$. Acesso em: 10 set. 2015.

RIVAS, N. P. P. et al. A (re)significação do trabalho docente no espaço escolar: currículo e formação. In: CONGRESSO ESTADUAL PAULISTA SOBRE FORMAÇÃO DE EDUCADORES, 8., 2005, São Paulo. Anais... São Paulo: Ed. da UNESP, 2007. p.6-13. Disponível em: <http://www.unesp.br/prograd/ebook\%20viii\%20cepfe/LinksArquivos/9eixo.pdf>. Acesso em: 8 set. 2015.

SCHÖN, D. Educando o profissional reflexivo. Porto Alegre: Artmed, 2000.

TEIXEIRA, M. A. P. Formação para diretor escolar da educação básica: o programa Nacional Escola de Gestores no estado do Paraná. 2011. 35f. Dissertação (Mestrado em Educação) - Setor de Educação, Universidade Federal do Paraná, Curitiba, 2011. 